IFAS Extension

\title{
Promoting Healthy Relationship Development in Teens, Part I: How Dating Smart in Youth Can Foster Better Relationships in Adulthood
}

Victor W. Harris, Gilon Marts, and Martie Gillen ${ }^{2}$

It was Franklin D. Roosevelt who brought national attention to the need for relationship education with this statement, "Today we are faced with the preeminent fact that, if civilization is to survive, we must cultivate the science of human relationships ... the ability of all peoples, of all kinds, to live together, in the same world, at peace." Cultivating healthy dating relationships that can lead to healthy adult romantic and marriage relationships is a science that reflects a complicated calculus of the premarital influences that may shape future relationship stability, quality, and satisfaction.

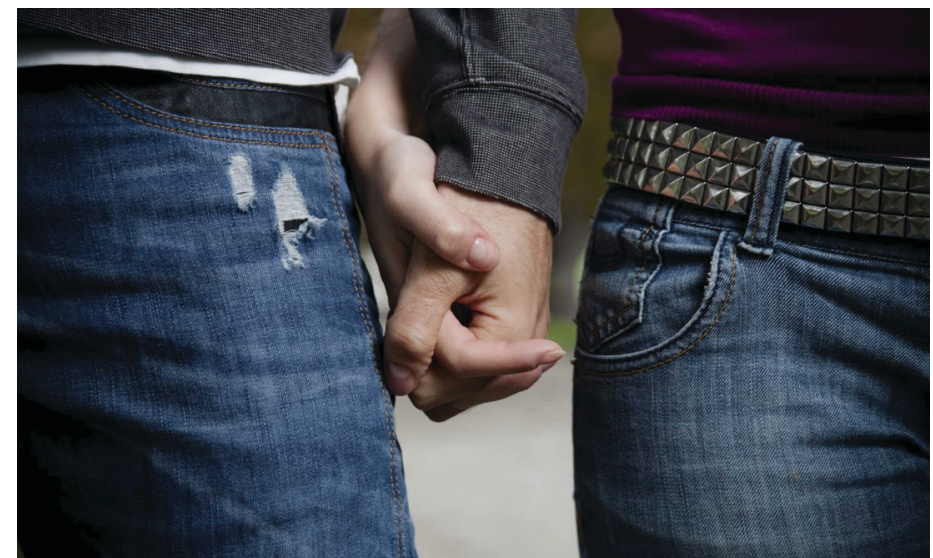

Figure 1. Healthy dating relationships can lead to healthy marriages. Credits: http://www.thinkstockphotos.com/

\section{Helpful Information}

Researchers have produced a general integrative framework of some of the primary premarital factors that can influence future marriage relationships. They have divided their framework into three general areas: 1) antecedent conditions; 2) adolescent attitudes, beliefs, and relationship behaviors; and, 3) adult circumstances and relationships (Karney et al. 2007).

- Antecedent Conditions. Background factors such as ethnicity/race, culture/religion, media, socioeconomic status, neighborhood environments, and education/ professional opportunities may influence adolescents and their ability to develop healthy dating and adult romantic relationships. Immediate influences, such as peer groups, school environments, family structure, relationships with family members, and exposure to stress, along with individual factors such as intelligence, personality, attachment style, self-esteem, delinquency, and substance abuse also influence a person's ability to develop healthy romantic relationships.

- Attitudes, beliefs, and relationship behaviors. Attitudes adopted about dating and marriage, beliefs about sex

1. This document is FCS2325, one of a series of the Family Youth and Community Sciences Department, Florida Cooperative Extension Service, Institute of Food and Agricultural Sciences, University of Florida. Original publication date March 2013. Visit the EDIS website at http://edis.ifas.ufl.edu.

2. Victor W. Harris, assistant professor and family life education Extension specialist, Department of Family, Youth and Community Sciences; Gilon Marts, student, Department of Family, Youth and Community Sciences; and Martie Gillen, assistant professor and family and consumer economics for older adults specialist, Department of Family, Youth and Community Sciences, Florida Cooperative Extension Service; Institute of Food and Agricultural Sciences, University of Florida, Gainesville, FL 32611. 
and childbearing, and relationships that individuals have been exposed to, specifically through media and their respective families of origin, shape their ability to develop healthy romantic relationships. Additionally, the timing of entry into romantic relationships, the intensity of these relationships, their duration and number, partner choices, sexual behavior choices, and potential consequences that may be associated with these choices, such as violence, STDs, and/or pregnancy, are also relevant factors that influence romantic relationships and future marital quality, stability, and satisfaction.

- Adult circumstances and relationships. Adult life circumstances include factors such as employment, mental health, educational attainment, and exposure to stress that may influence romantic relationships. Antecedent conditions and the attitudes, beliefs, and relationship behaviors developed in adolescence and early adulthood also exert varying levels of influence on the subsequent quality, stability, and satisfaction experienced in adult romantic and marital relationships.

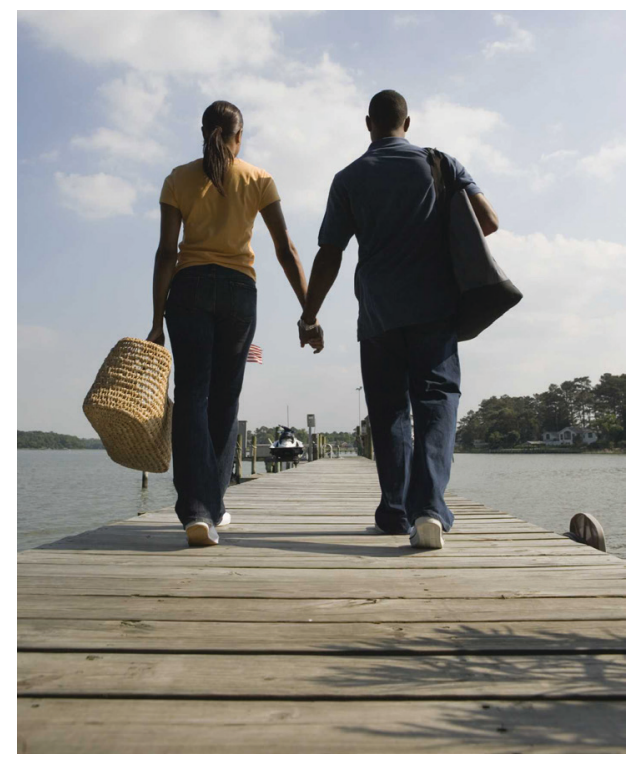

Figure 2. Multiple premarital factors can influence future marriage relationships. Credits: http://www.thinkstockphotos.com/

\section{Things You Can Use}

An understanding of the information below may be helpful in developing strategies for supporting healthy dating relationships that can, in turn, lead to healthy adult romantic and marriage relationships.

\section{Current Attitudes, Beliefs, and Relationship Behaviors}

While it may appear that today's youth are reluctant to marry, the reality is that their general attitudes and beliefs across race, ethnicity, and gender support the goals associated with healthy adult marital relationships. In fact, most plan to marry at some point (Karney et al. 2007).

\section{Support of Marriage}

Interestingly, males tend to support the notion of getting married and getting married at a later age more than females do. Hispanic, white, then black males are most supportive of marriage respectively. Unwed teen mothers tend to strongly support marriage. Although a majority of adolescents disapprove of divorce, they are realistic about the possibility that their marriages might end in divorce. People are marrying later in life, but they are still living together in young adulthood; cohabitation is considered acceptable among an increasing number of later teens and early adults (Karney et al. 2007).

\section{Nature of Romantic Relationships in Adolescence}

Early romantic relationships in middle school tend to focus on physical attraction, while later high school relationships tend to focus more on commitment and intimacy. The duration of romantic relationships generally increases with age and maturity, although some early romantic relationships may endure more than a year. Expressions of love and other emotions are common, including behaviors that express love, such as the giving and receiving of gifts.

Friendship-building typically moves from non-romantic to romantic relationships with age. Sexual behavior is most likely to be accepted and to occur in romantic relationships. Interestingly, while most high school teens believe that sexual intercourse is something that is "inappropriate," a majority become sexually active by the time they graduate from high school. Most report that they are "monogamous" sexually with only one partner within the past year. Low socio-economic status (SES) adolescents are more likely to have multiple sexual partners, thus increasing risks such as teen pregnancy and STDs. Approximately one in every ten teens reports being a part of a violent romantic relationship, with blacks, hispanics, and whites more likely to be involved in relationship violence, respectively.

Understanding antecedents, attitudes, beliefs, behaviors, and the circumstances surrounding dating relationships that may influence adult romantic and marriage relationships can be a helpful first step for promoting healthy relationship development. Identifying the actual predictors of healthy relationships is the next step toward helping people nurture the development of healthy dating relationships that can lead to quality, stable, and satisfying adult romantic 
and marriage relationships. The chart below, Premarital Predispositions (Table 1), highlights areas in which couples may be alike or different with an accompanying section to allow them to detail each of their observations. Take a minute to look at some of the premarital predispositions (i.e., antecedent conditions) below to help you better assess their potential needs as a couple.

Table 2 reviews the attitudes of the couple as a whole. Do they both plan to wed? Are their beliefs and feelings consistent with each other? The first three questions ask about the presence of violent behavior or sexual involvement in the relationship regardless of agreement. The last question asks about the nature of in-law interactions, specifically whether negativity is prevalent and corrosive to the couple's relationship.

\section{Helpful Resources}

Duncan, L., and V. W. Harris. 2012. Are you ready to get married? Healthy signs and red flags. Gainesville, FL: Cooperative Extension Service, Institute of Food and Agricultural Sciences, University of Florida. 4 pages. FCS2320. EDIS: http://edis.ifas.ufl.edu/fy1336

Harris, V. W., and G. Hinton. 2012. 10 things you need to know before you get married. Gainesville, FL: Cooperative Extension Service, Institute of Food and Agricultural Sciences, University of Florida. 5 pages. FCS2319. EDIS: http://edis.ifas.ufl.edu/fy1335

Harris, V. W., and G. Hinton. 2012. What do you see? Healthy dating that leads to healthy marriage. Gainesville, FL: Cooperative Extension Service, Institute of Food and Agricultural Sciences, University of Florida. 4 pages. FCS2322. EDIS: http://edis.ifas.ufl.edu/fy1338

Leslie, L. M., and V. W. Harris. 2012. Are you ready to tie the knot? A quick checklist. Gainesville, FL: Cooperative Extension Service, Institute of Food and Agricultural Sciences, University of Florida. 4 pages. FCS2318. EDIS: http://edis.ifas.ufl.edu/fy1334

Toelle, S. C., and V. W. Harris. 2012. Are you marrying someone from a different culture or religion? Gainesville, FL: Cooperative Extension Service, Institute of Food and Agricultural Sciences, University of Florida. 7 pages. FCS2318. EDIS: http://edis.ifas.ufl.edu/fy1337

\section{Source}

Karney, B. R., M. K. Beckett, R. L. Collins, and R. Shaw. 2007. Adolescent romantic relationships as precursors to healthy adult marriage - executive summary. Santa Monica, CA: Rand Corporation and the Department of Health and Human Services. Online: http://www.acf.hhs.gov/sites/ default/files/opre/adolescent_relationships.pdf 
Table 1. Premarital Predispositions

\begin{tabular}{|l|l|l|l|}
\hline \multicolumn{1}{|c|}{ Antecedent Conditions } & Same & Different & Comments/ Observations \\
\hline Race & & \\
\hline $\begin{array}{l}\text { Approval from integral relationships (i.e., } \\
\text { family, friends) }\end{array}$ & & \\
\hline Ethnicity & & \\
\hline Socioeconomic status & & \\
\hline Culture/religion & & \\
\hline Media & & \\
\hline Education & & \\
\hline Profession & & \\
\hline
\end{tabular}

Table 2. Potential Hotspots

\begin{tabular}{|c|c|c|c|}
\hline Do they agree? & Yes & No & Comments, Observations \\
\hline \multicolumn{4}{|l|}{ Values: intimacy, closeness } \\
\hline \multicolumn{4}{|l|}{ Beliefs: moral, religious } \\
\hline \multicolumn{4}{|l|}{$\begin{array}{l}\text { Behavior: gender roles, flexibility, } \\
\text { nonsexual touch }\end{array}$} \\
\hline \multicolumn{4}{|l|}{ Attitudes } \\
\hline \multicolumn{4}{|l|}{ Plan/desire to wed someday? } \\
\hline \multicolumn{4}{|l|}{ Childbearing? } \\
\hline \multicolumn{4}{|l|}{ Cohabitation: feelings/beliefs? } \\
\hline \multicolumn{4}{|l|}{ Thoughts on divorce? } \\
\hline \multicolumn{4}{|l|}{ Adult Interactions } \\
\hline \multicolumn{4}{|l|}{ Sexually involved? } \\
\hline \multicolumn{4}{|l|}{ Violent behavior present? } \\
\hline \multicolumn{4}{|l|}{ Controlling behavior present? } \\
\hline \multicolumn{4}{|l|}{ Time spent together/apart } \\
\hline \multicolumn{4}{|l|}{ Sexual behaviors } \\
\hline \multicolumn{4}{|l|}{ Money } \\
\hline In-law relations & & & \\
\hline
\end{tabular}

